\title{
UTILIZAÇÃO DE PILARES CERÂMICOS EM PRÓTESE SOBRE IMPLANTE:
} REVISÃO DE LITERATURA

\section{CERAMIC ABUTMENTS ON IMPLANT SUPPORTED TOOTH: A REVIEW}

\author{
Ana Paula Gambalonga de Jesus* \\ Felipe Cechinel Veronez" \\ Priscyla Waleska Simões****
}

\section{RESUMO}

A implantodontia sofreu muitos avanços na Odontologia moderna. As restaurações estéticas implanto-suportadas em dentes anteriores tornaram-se desafiadoras, pois os pilares protéticos utilizados para reter as próteses sobre implante são geralmente de titânio ou outros metais. Percebeu-se que esses implantes levam a uma coloração azul-acinzentada aos tecidos moles em pacientes com sorriso gengival ou biótipo fino. Para solucionar esse problema, pilares em cerâmica de zircônia ou alumina podem ser utilizados para permitir a eliminação de intercorrências quanto à cor e brilho metálico através do tecido peri-implantar. O resultado benéfico e a melhor adaptabilidade biológica e funcional estimulam o uso desses materiais. Esta revisão teve como finalidade descrever as principais características dos pilares cerâmicos, vantagens e desvantagens em relação aos metálicos, além das suas propriedades funcionais e biológicas.

Descritores: Estética dentária • Implantes dentários • Dente.

\section{ABSTRACT}

The dental implant had many advances in modern dentistry. The implant-supported restorations in anterior teeth, have become challenging because the abutments used for retaining the prosthesis on implants are usually made of titanium or other metals. It was found that these implants lead to a blue-gray coloration on the soft tissue in patients with gingival smile or thin biotype. To solve this problem, ceramic abutments of zirconia or alumina may be used to allow the elimination of complications with regard to the color and metallic luster through the peri-implant tissues. The good result and the best biological and functional adaptability stimulate the use of these materials. This review aimed to describe the main characteristics of ceramic abutments, advantages and disadvantages compared to the metal pillars, as also its functional and biological properties.

Descriptors: Esthetics, dental • Dental implants • Dental. 


\section{N T RO DUÇÃO}

Desde 1952, Branemark¹ pesquisou o conceito da osseointegração, que engloba o entendimento da capacidade curativa e reparadora dos tecidos moles e duros. Trabalho realizado com o foco em reabilitar os chamados inválidos orais, que são pacientes que tiveram a perda de todos os dentes da mandíbula e não obtiveram sucesso no uso de próteses totais mucossuportadas. Entretanto, após o sucesso do uso de implantes em próteses totais, foi relatada pela primeira vez em 1986 a utilização dessa modalidade de tratamento implanto-protética em dentes unitários ${ }^{2}$.

Desde 1986 até os dias atuais, houve uma enorme evolução na qualidade da osseointegração dos implantes, porém o sucesso dos implantes unitários não é mais definido exclusivamente pela permanência do mesmo. Embora essas taxas tenham atingido números extremamente elevados, o foco está mudando em direção a parâmetros estéticos, quando o resultado de uma restauração implanto-suportada é julgado ${ }^{3}$. Pelo aumento da exigência estética feita pelos pacientes ao clínico, há um acréscimo da importância na impressão visual da reconstrução protética no resultado final do tratamento. A falta de simetria gengival e a harmonia podem colocar o resultado estético em risco ${ }^{4}$.

Hoje, pilares personalizados podem ser fabricados a partir de diversos materiais, como metais ou cerâmicas, cada um com suas vantagens e desvantagens. Entre as desvantagens dos pilares de titânio, está a sua cor cinza escura, que pode causar uma descoloração acinzentada na mucosa peri-implantar, prejudicando o resultado estético nas reconstruções de implantes. Pilares cerâmicos de alta resistência confeccionados por cerâmicas de alumina e zircônia estão ganhando popularidade, tendo em vista a sua cor semelhante à estrutura dental, podendo ser utilizados em regiões onde a estética é primordial ${ }^{5}$, ${ }^{6}$. O design apropriado, o tratamento adequado do material e o pilar permitem ao clínico alcançar resultados estéticos que não eram possíveis com ligas de metais tradicionais ${ }^{3}$.

O contorno e a cor do pilar junto ao desenho individual da coroa do implante têm um papel imprescindível, uma vez que precisam estar adaptados e em perfeita harmonia óptica em relação às estruturas anatômicas adjacentes existentes. A configuração subgengival de uma restauração é um componente crucial, criando, assim, um perfil de emergência adequado, no qual o contorno gengival deve ser mantido fisiologicamente. Mantendo, dessa forma, a adequada manutenção do tecido conjuntivo e epitelial, que é um fator indispensável para o sucesso a longo prazo na implantodontia ${ }^{4}$.

O objetivo desta revisão de literatura é avaliar a qualidade dos pilares cerâmicos em restaurações implanto-suportadas em regiões estéticas, características físicas, funcionais e biológicas além de suas vantagens e desvantagens na sua utilização em relação aos pilares metálicos.

\section{MÉTODOS}

Pesquisa descritiva e exploratória, por meio de uma revisão de literatura narrativa, com análise qualitativa dos achados. A revisão de literatura foi realizada a partir de pesquisas eletrônicas. As bases acessadas foram o PubMed, MEDLINE, BIREME com artigos publicados entre 1983 a 2015. Os bancos de dados foram pesquisados utilizando-se os seguintes termos; "Ceramic abutment", "Esthetic" e "Dental", buscados através dos critérios predeterminados. Os critérios de inclusão para os artigos foram os aspectos abordados nas restaurações implanto-suportadas, suas características físicas, funcionais e biológicas. Foram levados em consideração: a substituição de um ou mais dentes perdidos por implantes em um determinado local na dentição, utilizando pilares cerâmicos em porções estéticas com o foco sobre o aspecto restaurador no procedimento clínico; a correlação entre a espessura da mucosa peri-implantar e possíveis descolorações causadas na utilização de pilares cerâmicos; estudos da longevidade e permanência dos pilares em comparações
JESUS APG

VERONEZ FC SIMÕES PW

UT I LI ZAÇÃO DE PILARES CERAMICOS EM PRÓTESE SOBRE IMPLANTE: REVISÃO DE LITERATURA

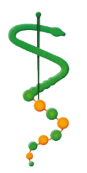

REV, ODONTOL. UNIV, CID, SÃO PAULO 2016; 28(3): 240-9, SET-DEZ 
JESUS APG

VERONEZ FC

SIMÕES PW

UT I LI ZAÇÃO

DE PILARES

CERÂMICOS EM

PRÓTESE SOBRE

IMPLANTE:

REVISÃO DE

LITERATURA

$242 \ldots$

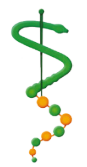

REV, ODONTOL,

UNIV, CID, SÃO

PAULO

$2016 ; 28(3)$ : $240-9$, SET-DEZ
I SSN 1983-5183

aos de zircônia e titânio com no mínimo (n-5) amostras e cinco anos de estudo apresentando taxas de complicações técnicas e biológicas; a utilização do sistema CAD/CAM para planejamento de próteses sobre implantes.

As buscas foram realizadas nos meses de agosto de 2015 a abril de 2016. O total de artigos obtidos através dessa busca foram 66 (sessenta e seis). Destes, 20 (vinte) artigos atenderam aos critérios de inclusão.

\section{REVISÃO DE LITERATURA}

A terapia com implantes dentários tem como principal objetivo o sucesso na osseointegração. No entanto, o êxito na implantodontia não é definido somente pela sua longevidade. Embora as taxas de permanência de implantes atinjam números extremamente elevados, o foco está mudando em direção a parâmetros estéticos quando o resultado de uma restauração implanto-suportada é julgado ${ }^{3}$.

Implante e estruturas de pilares baseados em metal, particularmente titânio, têm sido considerados, por muito tempo, a meIhor opção para restauração dentária implanto-suportada devido a seu bom comportamento mecânico e funcional. Há, no entanto, um aumento da procura clínica pelos pacientes por melhores níveis estéticos, não só em restaurações anteriores, mas também em posteriores. Tal desafio levou a seu rápido desenvolvimento e à introdução de diferentes sistemas protéticos à base de cerâmica ${ }^{7}$. Com a evolução da Odontologia em pilares estéticos, reconheceu-se que os pilares metálicos levam a uma coloração azul-acinzentada dos tecidos moles peri-implantares nas margens gengivais, o que foi considerado censurável por alguns clínicos para o sucesso do tratamento ${ }^{2}$. Como alternativa aos pilares metálicos, em situações de alta exigência estética, podem ser utilizados os pilares cerâmicos confeccionados com cerâmica de alta resistência. Os pilares cerâmicos podem ser fabricados a partir de materiais feitos de alumina de alta pureza densamente sintetizada $(\mathrm{Al} 2 \mathrm{O} 3)$ e a cerâmica de zircônia ( $\mathrm{ZrO} 2)$ estabilizada por ítrio (Y2O3). Ambos os materiais pos- suem ótimas propriedades ópticas e mecânicas ${ }^{8}$.

O uso da zircônia como material dentário começou a ganhar amplitude no início de 1900 e hoje, graças ao rápido desenvolvimento do design de fabricação assistida por computador auxiliado pela tecnologia CAD/CAM, o seu emprego aumentou significativamente ${ }^{9}$.

A zircônia é quimicamente um óxido e tecnologicamente um material restaurador, o qual não é solúvel em água, não citotóxico, tem uma aderência bacteriana baixa, é radiopaca, possui um baixo potencial de corrosão, boa estabilidade química e dimensional, resistência mecânica e tenacidade, juntamente com um módulo de Young na mesma ordem de grandeza das ligas de aço inoxidável. Nas fases iniciais de desenvolvimento, várias soluções foram testadas para sua aplicação biomédica, e nos anos seguintes pesquisas começaram a ser desenvolvidas focadas na zircônia tetragonal policristalina estabilizada por óxido de ítrio (Y-TZP) ${ }^{9,10 .}$

A zircônia é um polimorfo bem conhecido que ocorre em três formas: monoclínica $(\mathrm{M})$, cúbico $(\mathrm{C})$ e tetragonal $(\mathrm{T})$. A zircônia pura é monoclínica à temperatura ambiente. Essa fase é estável até $1170^{\circ} \mathrm{C}$. Acima dessa temperatura ela se transforma em tetragonal e, depois, na fase cúbica em $2370^{\circ} \mathrm{C}$. Durante o resfriamento após o processamento, ocorre a transformação da fase tetragonal em monoclínica, a uma faixa em torno de $970^{\circ} \mathrm{C}$. Essa transformação está associada a 3 a 4\% de expansão volumétrica, o óxido de ítrio é adicionado à composição da zircônia pura, para se estabilizar na forma tetragonal à temperatura ambiente. A expansão volumétrica que esse material sofre quando os cristais de zircônia passam da fase tetragonal para a monoclínica evita a propagação de trincas, aumentando a resistência do material ${ }^{10}$.

Um novo pilar cerâmico (CerAdapt, Nobel Biocare), feito de alumina densamente sintetizada, foi introduzido em 1993 para implantes Brånemark System (Nobel Biocare). As indicações propostas (coroas individuais e próteses parciais fixas em regiões anteriores e pré-molares) foram documentadas, incentivadas por 
resultados em estudos clínicos prospectivos. A alumina, bem como o dióxido de zircônia, é caracterizada pela boa compatibilidade com o tecido, baixo potencial de corrosão, baixa condutividade térmica e propriedades mecânicas superiores em comparação com as cerâmicas convencionais. Porém, a zircônia tem uma resistência à flexão, 900 a 1,200 MPa, e tenacidade quase duas vezes maior que a alumina ${ }^{411}$. Possui, ainda, o dobro da resistência flexural das cerâmicas de alumina $(\mathrm{Al} 2 \mathrm{O} 3)^{8}$.

É importante que os estudos que avaliam os resultados dos pilares protéticos definam a região dentária pesquisada, como as suas complicações, pois os resultados de permanência podem ser significativamente diferentes. A região de pré-molares e molares atua com forças oclusais quase duas e três vezes maiores, respectivamente, quando comparada com a região de anteriores. Portanto, os resultados clínicos entre os pilares anteriores e posteriores podem ser significativamente diferentes. Além disso, os parâmetros estéticos que regem a seleção de um pilar anterior podem não se aplicar necessariamente a regiões posteriores ${ }^{2}$.

\section{Função, Mecânica e Biologia}

Pilares metálicos e cerâmicos apresentam caraterísticas distintas no comportamento funcional, mecânico e biológico. Sendo necessárias, assim, a avaliação e a comparação dessas estruturas através de pesquisas clínicas e laboratoriais, para assim mensurar as suas qualidades ${ }^{12}$.

Quarenta e oito coroas cerâmicas padronizadas em incisivos centrais superiores (Procera) em óxido de alumina foram utilizadas em um estudo para observar qual pilar teria a menor resistência. Foram separados em três grupos, quais sejam: grupo-controle Ti, pilares de titânio; Grupo Al, pilares de alumina; Grupo Zr, pilares de zircônia com (n-16) para cada grupo. Os elementos de estudos foram expostos artificialmente a 1.200 .000 ciclos por meio de carregamento dinâmico e de ciclos térmicos em meio bucal artificial, simulando cinco anos de função. Em seguida, todas as amostras foram testadas para observar a resistência à fratura, usando-se carga compressiva na superfície palatal das coroas. Os resultados expostos mostraram que todas as amostras resistiram ao processo de envelhecimento artificial, recorrendo-se à simulação das condições bucais e que nenhum afrouxamento de parafuso foi registrado, concluindo-se que os três tipos de restaurações implanto-suportadas possuem potencial para suportar forças oclusais fisiológicas em região anterior $^{8}$.

Em outro estudo, foram fabricados pela Procera System (Nobel Biocare) três grupos de pilares para prova: de óxido de alumínio, de zircônia e de titânio, sendo o (n-15) para cada grupo. Foram aplicados 47.250 ciclos na máquina de ensaios mecânicos a uma carga dinâmica de compressão entre 20 e $200 \mathrm{~N}$ a $1 \mathrm{~Hz}$ em uma área nos pilares cimentados. Foram realizadas medições de microgaps na interface implante-pilar por vestibular, palatina, mesial e distal de cada pilar em microscópio eletrônico de varredura, com análise antes e após as experiências. Após os ciclos de testes, o grupo-controle do pilar em titânio revelou um aumento de microgap de $3.47 \mathrm{~mm}, 1,45 \mathrm{~mm}$ nos pilares de zircônia e 1,82mm nos grupos de alumina. Não houve diferença estatística entre os grupos, concluindo-se que os pilares cerâmicos podem suportar forças funcionais como os pilares de titânio convencionais $^{12}$.

Em uma revisão sistemática de literatura, realizada através de vinte e sete estudos que descreveram os resultados dos pilares de implantes em região anterior, foi encontrada uma média de fracasso de $1,15 \%$, atribuída a fraturas em pilares de cerâmica; foram relatadas oito fraturas em pilares de alumina e três em zircônia, em um total de onze fraturas, porém não foram relatadas fraturas em pilares de titânio. Por causa da grande heterogeneidade dos dados, a permanência dos mesmos não foi calculada ${ }^{2}$. Coroas de cerâmica pura associadas a pilares cerâmicos exibiram taxas de fraturas anuais similares às de coroas metalo-cerâmicas apoiadas em pilares metálicos ${ }^{13}$. Em uma pesquisa com cinquenta e três próteses sobre implantes em vinte e seis pacientes, o afrouxamento do parafuso do pilar em zircônia ocorreu em duas restaurações no oitavo e vigési-
JESUS APG VERONEZ FC SIMÕES PW

UTILIZAÇÃO DE PILARES CERÂMICOS EM PRÓTESE SOBRE IMPLANTE: REVISÃO DE LITERATURA

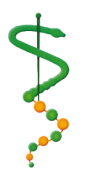

REV, ODONTOL. UNIV, CID, SÃO PAULO 2016; 28(3): 240-9, SET-DEZ 
JESUS APG

VERONEZ FC

SIMÕES PW

UT I LIZAÇÃO

DE PILARES

CERAMICOS EM

PRÓTESE SOBRE

IMPLANTE :

REVISÃO DE

LITERATURA

$244 \ldots$

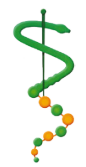

REV. ODONTOL,

UNIV. CID . SÃO

PAULO

2016; 28(3): 240-9, SET-DEZ :

I SSN 1983-5183

mo sétimo mês, respectivamente ${ }^{11 .}$

Em outro estudo, foram testadas as taxas de permanência, as complicações técnicas e biológicas em implantes com pilares de zircônia e titânio após cinco anos de uso, associados a coroas metalo-cerâmicas em região de canino e dentes posteriores. Dezoito pacientes com dezoito pilares de zircônia e dez pilares de titânio foram avaliados por uma média de acompanhamento de 5 anos. Nenhuma fratura do pilar ocorreu. Assim, a taxa de permanência foi de $100 \%$ para ambos. Sendo que não houve diferenças relevantes, clinicamente ou estatisticamente, em taxas de permanência entre cinco anos, e taxas de complicações técnicas e biológicas em pilares de zircônia e titânio em regiões posteriores ${ }^{9}$.

Uma complicação encontrada, em seis estudos, utilizando pilares pré-fabricados (titânio), foi a recessão da mucosa peri-implantar ${ }^{2}$. A mucosa peri-implantar é geralmente reconhecida como um tecido cicatricial hipocelular e hipovascular. São imunologicamente muito inferiores aos tecidos periodontais ao redor dos dentes, uma vez que exibe uma resistência prejudicada à colonização bacteriana ${ }^{14}$.

Em uma pesquisa, os autores avaliaram a saúde peri-implantar com pilares cerâmicos, e a maioria dos tecidos não mostraram sinais de inflamação, apresentando uma aparência saudável. Foram feitas análises microbiológicas em outros estudos, nos quais não foi encontrada nenhuma diferença na colonização primária entre os pilares de zircônia e titânio ${ }^{3}$. Não foram observadas complicações biológicas nos sítios com pilares em zircônia, nem em locais em titânio. Porém, foi detectado ligeiramente mais placa em reconstruções em pilares de titânio do que em pilares de zircônia9.

Desse modo, constata-se que a reação dos tecidos duros e moles em pilares de zircônia foi mais favorável ${ }^{11}$. A zircônia $Y$ -TZP possui um acúmulo menor de bactérias em detrimento dos pilares de titânio ${ }^{15}$. Autores também concluíram que a zircônia, quando utilizada no colar gengival ou no pilar do implante, apresenta aderência no tecido conjuntivo semelhante ao que foi observado nas superfícies de titânio ${ }^{3}$.
O contorno e a cor do pilar requerem adaptação ideal aos existentes achados anatômicos, os quais devem ser mantidos fisiologicamente precisos tanto quanto possível. A manutenção do tecido conjuntivo e a inserção epitelial são fatores de longo prazo indispensáveis para o sucesso da implantodontia, uma vez que a configuração de uma restauração subgengival é um componente crucial na integridade biológica e aceitação estética ${ }^{4}$.

\section{Estética}

A escolha dos pilares de implantes na região anterior está diretamente associada a diversos fatores, como: a linha do sorriso do paciente (baixa, média, alta, ou sorriso gengival), a natureza da mucosa peri-implantar (grossa ou fina), angulação do implante, escolha do material da coroa, disponibilidade de espaço restaurador, tipo de restauração (parafusada ou cimentada), preferência do clínico e despesas de tratamento. Diferentes tipos de pilares de implantes têm sido descritos na literatura para utilização na região anterior. Eles podem ser classificados com base no método de conexão para restauração, no material, no método de fabricação e na cor ${ }^{2}$.

As propriedades ópticas dos materiais, no entanto, são não os determinantes exclusivos para o sucesso estético. Um projeto tridimensional adequado dos materiais cerâmicos são fatores-chave para o máximo proveito das propriedades ópticas e alcance dos resultados estéticos. A tecnologia CAD/CAM tornou-se um elemento integrante da moderna odontologia e tecnologia de laboratório, tendo em vista que se trata de uma ferramenta extremamente útil para desenhar adequadamente os pilares do implante em maneiras de fornecer suporte ideal para os tecidos moles circundantes. Alguns sistemas permitem que o técnico de prótese dentária a desenhe completamente no computador, sem a necessidade de um padrão, uma vez que a espessura do material e as características de design são facilmente controladas $^{3}$. A utilização de CAD/CAM parece ser um tratamento previsível com os melhores resultados estéticos na região anterior da maxila, pois desempenha um papel importante na instalação de implante e correções protéticas. Além disso, essa 
ferramenta parece melhorar a presença da papila entre o dente e implante unitário ${ }^{16}$.

As complicações estéticas tendem a ser mais frequentes em pilares metálicos ${ }^{13} \mathrm{e}$, em contrapartida, os pilares de zircônia possuem melhor estética e podem restabelecer a silhueta mais natural no aspecto de cor e saúde dos tecidos moles peri-implantares em comparação aos pilares de titânio em pacientes com linha de sorriso alta, tendo a zircônia a capacidade natural em transmitir luz ${ }^{17,18}$.

Foi realizado um estudo com um grupo de doze pacientes com implantes unitários de titânio na região anterior da maxila. Todos os implantes (n-12) foram restaurados com pilares de zircônia e coroas cerâmicas totais. Foram feitas, nas unidades de teste, medições de cor da mucosa peri-implantar nas faces dos dentes, usando um espectrofotômetro. O pilar testado teve a cor do tecido mole peri-implantar alterado. Na área crítica marginal, cinco dos doze pacientes não diferenciaram o tecido da gengiva e dos dentes naturais ${ }^{19}$.

Um estudo para avaliação da aparência das coroas de implantes em dentes unitários revelou que mais de $60 \%$ dos casos mostraram uma incompatibilidade entre a cor dos tecidos moles da restauração do implante e a gengiva do dente natural. Este foi identificado como um grande problema, sobretudo nas restaurações de implantes em zona estética ${ }^{19}$. Em geral, estudos utilizando a análise espectrofotométrica mostraram menores descolorações peri-implantares da mucosa para pilares de zircônia em comparação com pilares metálicos; entretanto, utilizando escores subjetivos/objetivos, não houve diferença na satisfação estética do paciente entre os dois tipos de pilares².

A espessura do tecido mole, no entanto, parece desempenhar um papel importante no grau de alteração de cor pelo metal e dos materiais cerâmicos. Enquanto que diferenças de cor nos tecidos moles podem ser detectadas em espessuras de até $2 \mathrm{~mm}$, nenhuma mudança na cor pode ser distinguida, ao olho humano, em uma mucosa com $3 \mathrm{~mm}$ de espessura ${ }^{3}$.

Colaborando com esse resultado, em outra pesquisa foram utilizados dez maxilares de suínos, sendo a área palatal esco-
Ihida como a região de teste, para simular diferentes espessuras da mucosa. Foram utilizados enxertos de tecido conjuntivo com $0,5 \mathrm{~mm}$ e $1,0 \mathrm{~mm}$ de espessura. Autores definiram a espessura da mucosa colocando os enxertos sob um retalho na mucosa palatal. Quatro diferentes corpos de prova de titânio (titânio, titânio revestido com cerâmica feldspática, zircônia e zircônia revestida com cerâmica feldspática) foram colocados sob a mucosa, e a cor do tecido foi avaliada com um espectrofotômetro para as três diferentes espessuras dos tecidos moles (1,5 2,0, e $3,0 \mathrm{~mm})$. A cor foi comparada com a mucosa sem amostras testes e a diferença de cor foi calculada. Todos os materiais restauradores induziram mudanças globais na cor que diminuiu com o aumento da espessura dos tecidos moles. O titânio induziu a mais proeminente mudança de cor. A zircônia não induziu alterações de cores visíveis em $2,0 \mathrm{~mm}$ e $3,0 \mathrm{~mm}$ de espessura. No entanto, com uma espessura de 3,0mm da mucosa, nenhuma mudança na cor podia ser distinguida pelo olho humano em qualquer amostra. Dessa forma, a espessura da mucosa configura um fator crucial em termos de descolorações causadas por diferentes materiais restauradores, de modo que, em pacientes com mucosa mais fina, a zircônia irá mostrar menor mudança cromática ${ }^{20}$.

\section{I S CUSSÃO}

Os pilares em titânio foram considerados, por muito tempo, a melhor opção para restauração dentária implanto-suportada, devido a seu bom comportamento mecânico e funcional. Entretanto, os resultados de um estudo concluíram que os três tipos de restaurações implanto-suportadas utilizando pilares em titânio, alumina e zircônia possuem capacidade para suportar forças oclusais em região anterior ${ }^{8}$. Tais dados estão de acordo com os resultados de outra pesquisa que, utilizando os mesmos três tipos de materiais, demonstrou que não houve diferença entre os grupos, concluindo que os pilares cerâmicos podem suportar forças funcionais como os pilares de titânio convencionais ${ }^{12}$.

Em uma revisão sistemática de literatura com 27 (vinte e sete) estudos, foi encon-
JESUS APG VERONEZ FC SIMÕES PW

UTILIZAÇÃO DE PILARES CERÂMICOS EM PRÓTESE SOBRE IMPLANTE: REVISÃO DE LITERATURA 
JESUS APG

VERONEZ FC

SIMÕES PW

UT I LI ZAÇÃO

DE PILARES

CERAMICOS EM

PRÓTESE SOBRE

IMPLANTE:

REVISÃO DE

LITERATURA

$246 \ldots$

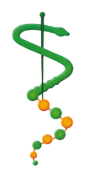

REV, ODONTOL,

UNIV. CID, SÃO

PAULO

$2016 ; 28(3):$

$240-9$, SET-DEZ trada uma média de fracasso em 1,15\% atribuível aos pilares cerâmicos ${ }^{2}$. Concordando com esse achado, nenhuma fratura do pilar em zircônia e titânio ocorreu após cinco anos de uso segundo Zembic ${ }^{9}$. Dessa forma, a taxa de permanência foi de $100 \%$ para ambos, demonstrando-se, assim, através desses estudos, que a taxa de sucesso, no quesito manutenção dos pilares é alta tanto para os pilares cerâmicos como para os pilares de titânio ${ }^{9}$.

A zircônia, quando utilizada no colar gengival ou no pilar do implante, possui uma aderência no tecido conjuntivo semeIhante à das superfícies de titânio ${ }^{3}$. Além disso, pesquisas apontam que há um acúmulo menor de placa bacteriana em pilares cerâmicos ${ }^{9,15}$, e estudos longitudinais não encontraram alterações na mucosa peri-implantar, onde os mesmos se mostraram saudáveis, sem sinal de alterações fisiológicas dos tecidos ${ }^{3}$. Esses achados podem contribuir na escolha correta do pilar, diminuindo, assim, a incidência da ocorrência de fistula, que é a complicação biológica mais comum encontrada ${ }^{2}$.

Os pilares de zircônia possuem melhores propriedades estéticas e podem restabelecer a silhueta mais natural, no aspecto de cor e saúde dos tecidos moles peri-implantares ${ }^{13,17,18}$. Uma análise espectrofotométrica mostrou menores alteração de cor peri-implantar da mucosa para pilares de zircônia em comparação com pilares metálicos. Colaborando com esse achado, foram avaliados 12 (doze) pilares de zircônia, nos quais houve alteração da cor do tecido mole peri-implantar, porém na área crítica marginal, cinco dos doze pacientes não diferenciaram o tecido da gengiva e dos dentes naturais ${ }^{19}$. Entretanto, é necessário considerar que, clinicamente, a escolha do material do pilar não atua isoladamente, sendo que pode não haver diferença na satisfação estética do paciente entre os dois tipos de pilares ${ }^{2}$, uma vez que a espessura da mucosa é um fator crucial em áreas estéticas. Assim, tendo a priori a avaliação do fenótipo gengival do paciente, aqueles com mucosas mais finas devem ter preferência por pilares cerâmicos, tendo em vista que estes apresentam menor mudança cromática ${ }^{20}$.

A tecnologia CAD/CAM trouxe maiores proveitos das propriedades ópticas dos pilares cerâmicos, sendo hoje parte integrante da odontologia moderna. A fresagem dos componentes, trazendo características personalidades para cada caso e podendo ser útil no desenho de pilares, traz uma melhora na presença da papila entre dente e implante. Essa característica não deve ser descartada na escolha do pilar, pois não somente a escolha do material, mas também como esse material é utilizado e confeccionado, são imprescindíveis em áreas com grande exigência estética ${ }^{16}$.

\section{TABELAS}

As tabelas a seguir identificam os estudos que foram analisados anteriormente, indicando os autores, o ano, o número de amostras utilizadas, os grupos analisados e os resultados obtidos.

\section{CONCLUSÃO}

A presente revisão de literatura mostra dados relevantes segundo os quais a zircônia exibe melhores vantagens mecânicas em comparação à alumina. Quando os pilares de cerâmica são comparados aos pilares de titânio, são poucos os indícios de maiores fraturas, podendo ambos os materiais serem indicados em áreas anteriores e posteriores. Assim, também, são meIhores os níveis estéticos, principalmente em reabilitações implanto-suportadas em regiões anteriores, onde o paciente pode apresentar biótipo gengival fino ou linha do sorriso alta. Em relação ao comportamento biológico há pouca diferença entre pilares de zircônia e titânio, porém, os pilares cerâmicos parecem demonstrar melhor adaptabilidade aos tecidos peri-implantares. Maiores pesquisas devem ser feitas quanto ao comportamento biológico e estético de pilares em cerâmica. 
TABELA 1 - Estudos dos pilares em titânio, zircônia e alumina

\begin{tabular}{|c|c|c|c|}
\hline AUTOR/ANO & AMOSTRAS & GRUPOS & RESULTADOS \\
\hline $\begin{array}{c}\text { ATT et al. }{ }^{8 /} \\
2006\end{array}$ & & $\begin{array}{l}\text { Titânio (n16) } \\
\text { Zircônia (n16) } \\
\text { Alumina (n16) }\end{array}$ & $\begin{array}{l}\text { Os três tipos de restaurações im- } \\
\text { planto-suportadas possuem poten- } \\
\text { cial para suportar forças oclusais } \\
\text { fisiológicas em região anterior. }\end{array}$ \\
\hline $\begin{array}{c}\text { YUZUGULLU12/ } \\
2008\end{array}$ & 45 & $\begin{array}{l}\text { Titânio (n15) } \\
\text { Zircônia (n15) } \\
\text { Alumina (n15) }\end{array}$ & $\begin{array}{l}\text { Não houve diferença entre os gru- } \\
\text { pos, concluindo-se que os pilares } \\
\text { cerâmicos podem suportar forças } \\
\text { funcionais como os pilares de titâ- } \\
\text { nio convencionais. }\end{array}$ \\
\hline $\mathrm{ZEMBIC}^{9} / 2013$ & 28 & $\begin{array}{l}\text { Zircônia(n18)* } \\
\text { Titânio(n10) }\end{array}$ & $\begin{array}{l}\text { Não houve diferenças relevantes } \\
\text { clinicamente ou estatisticamente } \\
\text { em taxas de permanência entre } \\
\text { cinco anos, e taxas de complica- } \\
\text { ções técnicas e biológicas em pila- } \\
\text { res de zircônia e titânio em regiões } \\
\text { posteriores. }\end{array}$ \\
\hline $\begin{array}{l}\text { GLAUSER }{ }^{11 /} \\
2004\end{array}$ & 53 & Zircônia(n53) & $\begin{array}{l}\text { Pilares em zircônia ofereceram es- } \\
\text { tabilidade suficiente para suportar } \\
\text { reconstruções de implante de den- } \\
\text { tes unitários em regiões anteriores } \\
\text { e pré-molares. }\end{array}$ \\
\hline $\begin{array}{l}\text { HAPPE et al. }{ }^{19} \\
2013\end{array}$ & 12 & Zircônia(n12) & $\begin{array}{l}\text { O desenho testado de } \mathrm{n} 12 \text { pilares } \\
\text { em zircônia alterou a cor do teci- } \\
\text { do mole peri-implantar. Porém, na } \\
\text { área crítica marginal, cinco dos } \\
\text { doze pacientes não diferenciaram } \\
\text { o tecido da gengiva e dos dentes } \\
\text { naturais. }\end{array}$ \\
\hline $\begin{array}{c}\text { JUNG et al., }{ }^{20} \\
\text { /2007 }\end{array}$ & $\begin{array}{l}\text { Não foi for- } \\
\text { necido }\end{array}$ & $\begin{array}{c}\text { Titânio } \\
\text { Zircônia } \\
\text { Titânio revesti- } \\
\text { do com cerâ- } \\
\text { mica feldspá- } \\
\text { tica } \\
\text { Zircônia } \\
\text { revestida com } \\
\text { cerâmica felds- } \\
\text { pática }\end{array}$ & $\begin{array}{l}\text { Todos os materiais restauradores } \\
\text { induziram mudanças globais na } \\
\text { cor a qual diminuiu com o aumen- } \\
\text { to da espessura dos tecidos moles. } \\
\text { O titânio induziu a mais proemi- } \\
\text { nente mudança de cor. A zircônia } \\
\text { não induziu alterações de cores } \\
\text { visíveis em 2,0mm e } 3,0 \mathrm{~mm} \text { de } \\
\text { espessura. No entanto, com uma } \\
\text { espessura de 3,0mm da mucosa, } \\
\text { nenhuma mudança na cor podia } \\
\text { ser distinguida pelo olho humano } \\
\text { em qualquer amostra. }\end{array}$ \\
\hline
\end{tabular}

* As amostras iniciaram com n40 para os dois grupos em titânio e zircônia. Após cinco anos de acompanhamento, estavam disponíveis amostras n10 e n18 respectivamente. 
JESUS APG

VERONEZ FC

SIMÕES PW

UT I LIZAÇÃO

DE PILARES

CERÂMICOS EM

PRÓTESE SOBRE

IMPLANTE :

REVISÃO DE

LITERATURA

TABELA 2 - Revisão sistemática

\begin{tabular}{|l|l|l|l|}
\hline AUTOR/ ANO & $\%$ & $\begin{array}{l}\text { NÚMERO DE } \\
\text { ARTIGOS }\end{array}$ & RESULTADOS \\
\hline $\begin{array}{l}\text { BIDRA E RUNGRU- } \\
\text { ANGANUNT / 2013 }\end{array}$ & 27 & $\begin{array}{l}\text { Mínimas fraturas nos pilares cerâ- } \\
\text { micos em regiões anteriores têm } \\
\text { sido relatadas. Estudos utilizando } \\
\text { espectrofotometria mostraram } \\
\text { menor descoloração gengival com } \\
\text { pilares de zircônia. Porém, não há } \\
\text { nenhuma evidência para diferente } \\
\text { satisfação estética do paciente en- } \\
\text { tre pilares de cerâmica e metal. }\end{array}$ \\
\hline
\end{tabular}

* Falha média restrita aos pilares cerâmicos

\section{REFERÊNCIAS}

1. Branemark PI. Osseointegration and its experimental background. The Journal of prosthetic dentistry 1983 Sep;50(3):399-410.

2. Bidra AS, Rungruanganunt P. Clinical outcomes of implant abutments in the anterior region: a systematic review. Journal of esthetic and restorative dentistry : official publication of the American Academy of Esthetic Dentistry [et al] 2013 Jun;25(3):159-76.

3. Blatz MB, Bergler M, Holst S, Block MS. Zirconia abutments for single-tooth implants--rationale and clinical guidelines. Journal of oral and maxillofacial surgery : official journal of the American Association of Oral and Maxillofacial Surgeons 2009 Nov;67(11 Suppl):74-81.

4. Yildirim M, Edelhoff D, Hanisch O, Spiekermann H. Ceramic abutments--a new era in achieving optimal esthetics in implant dentistry. The International journal of periodontics \& restorative dentistry 2000 Feb;20(1):81-91.

5. Zembic A, Sailer I, Jung RE, Hammerle $\mathrm{CH}$. Randomized-controlled clinical trial of customized zirconia and titanium implant abutments for single-tooth implants in canine and posterior regions: 3-year results. Clinical oral implants research 2009 Aug;20(8):802-8.
6. Nothdurft F, Pospiech P. Prefabricated zirconium dioxide implant abutments for single-tooth replacement in the posterior region: evaluation of peri-implant tissues and superstructures after 12 months of function. Clinical oral implants research 2010 Aug;21(8):857-65.

7. Jiménez-Melendo M, Llena-Blasco $O$, Bruguera A, Llena-Blasco J, Yáñez-Vico R-M, García-Calderón M, et al. Mechanical behavior of single-layer ceramized zirconia abutments for dental implant prosthetic rehabilitation. Journal of Clinical and Experimental Dentistry 2014;6(5):e485-e90.

8. Att W, Kurun S, Gerds T, Strub JR. Fracture resistance of single-tooth implant-supported all-ceramic restorations: an in vitro study. The Journal of prosthetic dentistry 2006 Feb;95(2):111-6.

9. Zembic A, Bosch A, Jung RE, Hammerle $\mathrm{CH}$, Sailer I. Five-year results of a randomized controlled clinical trial comparing zirconia and titanium abutments supporting single-implant crowns in canine and posterior regions. Clinical oral implants research 2013 Apr;24(4):384-90.

10. Piconi C, Maccauro G. Zirconia as a ceramic biomaterial. Biomaterials 1999 Jan;20(1):1-25.
REV, ODONTOL.

UNIV, CID, SÃO PAULO

$2016 ; 28(3):$ 240-9, SET-DEZ 
11. Glauser R, Sailer I, Wohlwend A, Studer S, Schibli M, Scharer P. Experimental zirconia abutments for implant-supported single-tooth restorations in esthetically demanding regions: 4-year results of a prospective clinical study. The International journal of prosthodontics 2004 May-Jun;1 7(3):285-90.

12. Yuzugullu B, Avci M. The implant-abutment interface of alumina and zirconia abutments. Clinical implant dentistry and related research 2008 May;10(2):113-21.

13. Sailer I, Zembic A, Jung RE, Siegenthaler D, Holderegger $\mathrm{C}$, Hammerle $\mathrm{CH}$. Randomized controlled clinical trial of customized zirconia and titanium implant abutments for canine and posterior single-tooth implant reconstructions: preliminary results at 1 year of function. Clinical oral implants research 2009 Mar;20(3):219-25.

14. Gehrke P, Tabellion A, Fischer C. Microscopical and chemical surface characterization of CAD/CAM zircona abutments after different cleaning procedures. A qualitative analysis. The Journal of Advanced Prosthodontics 2015;7(2):151-9.

15. Rimondini L, Cerroni L, Carrassi A, Torricelli P. Bacterial colonization of zirconia ceramic surfaces: an in vitro and in vivo study. The International journal of oral \& maxillofacial implants 2002 Nov-Dec;17(6):793-8.
16. Borges T, Lima T, Carvalho Á, CarvaIho V. Clinical Outcome of Inter-Proximal Papilla between a Tooth and a Single Implant Treated with CAD/ CAM Abutments: a Cross-Sectional Study. Journal of Oral \& Maxillofacial Research 2012 Jul-Sep;3(3):e4.

17. De Medeiros RA, Vechiato-Filho AJ, Pellizzer EP, Mazaro JV, Dos Santos DM, Goiato MC. Analysis of the peri-implant soft tissues in contact with zirconia abutments: an evidence-based literature review. The journal of contemporary dental practice 2013 May 01;14(3):567-72.

18. Vigolo P, Fonzi F, Majzoub Z, Cordioli G. An in vitro evaluation of ZiReal abutments with hexagonal connection: in original state and following abutment preparation. The International journal of oral \& maxillofacial implants 2005 Jan-Feb;20(1):108-14.

19. Happe A, Schulte-Mattler V, Fickl S, Naumann M, Zoller JE, Rothamel D. Spectrophotometric assessment of peri-implant mucosa after restoration with zirconia abutments veneered with fluorescent ceramic: a controlled, retrospective clinical study. Clinical oral implants research 2013 Aug;24 Suppl A100(28-33.

20. Jung RE, Sailer I, Hammerle CH, Attin T, Schmidlin P. In vitro color changes of soft tissues caused by restorative materials. The International journal of periodontics \& restorative dentistry 2007 Jun;27(3):251-7.

Recebido em 05/07/2016

Aceito em 01/12/2016
JESUS APG

VERONEZ FC

SIMÕES PW

UT I L I ZAÇÃO

DE PILARES

CERAMICOS EM

PRÓTESE SOBRE

IMPLANTE:

REVISÃO DE

LITERATURA

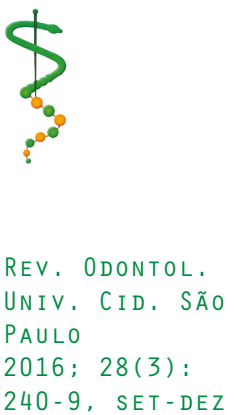

